\title{
PENGARUH MUSIK "STAYIN ALIVE" TERHADAP KUALITAS KOMPRESI RESUSITASI JANTUNG PARU OLEH MAHASISWA PERAWAT
}

\author{
Imardiani $^{1}$, Miranti Florencia Iswari ${ }^{2}$ \\ ${ }^{1,2}$ IKesT Muhammadiyah Palembang \\ imaru.diani11@gmail.com
}

\begin{abstract}
ABSTRAK
Resusitasi Jantung Paru (RJP) merupakan tindakan pengembalian aliran parsial darah teroksigenasi sampai sirkulasi darah kembali spontan. Salah satu metode mempertahankan kualitas kompresi RJP yaitu dengan musik "Stayin Alive" karena memiliki irama teratur dengan kecepatan $103 \mathrm{bpm}$. Tujuan penelitian untuk mengetahui pengaruh musik "Stayin Alive" terhadap kualitas kompresi RJP frekuensi dan kedalaman RJP oleh mahasiswa perawat. Penelitian ini merupakan penelitian kuantitatif dengan Metode Quasy-Experiment Pre test Posttest with Control Group Design. Pemilihan sampel secara total sampling dengan jumlah 70 mahasiswa Profesi Ners kemudian dirandomisasi dan dibagi menjadi dua kelompok yaitu kelompok intervensi dan kelompok kontrol. Pada kelompok intervensi saat melakukan kompresi sambil mendengarkan irama musik lagu "Stayin Alive", sedangkan kelompok kontrol dengan perhitungan "Rule of Five". Analisis data menggunakan Uji Mann Whitney untuk analisis tidak berpasangan. Penelitian menunjukkan hasil tidak ada perbedaan yang signifikan rerata frekuensi dan kedalaman RJP antara kelompok intervensi dengan kelompok kontrol nilai $p$-value $=0,381$ $(\mathrm{p}>0,05)$ untuk frekuensi RJP dan $p$-value $=0,295(\mathrm{p}>0,05)$ untuk frekuensi kedalaman RJP. Kesimpulan Intervensi musik "Stayin Alive" dan "Rule of Five" sama-sama mampu meningkatkan kualitas kompresi RJP baik frekuensi maupun kedalaman karena tidak ada perbedaan yang signifikan antara kelompok intervensi dan kontrol
\end{abstract}

Kata kunci : kualitas kompresi RJP, musik stayin alive, resusitasi jantung paru

\section{THE INFLUENCE OF MUSIC ON THE QUALITY OF CPR COMPRESSION IN NURSE STUDENTS}

\section{ABSTRACT}

Pulmonary Heart Resuscitation (CPR) is the partial flow of oxygenated blood until blood circulation returns spontaneously. One method to maintain the compression quality is using music "Stayin Alive" because it has a regular rhythm with a speed of $103 \mathrm{bpm}$. This research determined the effect of music "Stayin Alive" on CPR compression quality, frequency, and CPR depth by student nurses. This research was quantitative research with a quasi-experiment pre-test post-test with control group design. The total sampling technique was employed to select 70 preservice nurses who were then randomly divided into two groups; the experiment and control groups. The experiment group listened to the song "Stayin Alive" while performing the CPR compression. At the same time, the control group used the rule of five methods. The data obtained from those groups were analyzed using the Mann-Whitney tests for unpaired analysis. The results of this research showed the insignificant difference between the average frequency and depth of $C P R$ compression between the experiment group and control group with $p=0.381(p>0.05)$ and $p=0.295$ ( $p>0.05)$ for the depth of the compression. Conclusion Stayin Alive and rule of five music intervention can improve the quality of CPR compression both frequency and depth because research showed significant between the experiment group and control 
group.

Keywords: cardiopulmonary resuscitation, CPR compression quality, music staying alive.

\section{PENDAHULUAN}

Resusitasi Jantung Paru (RJP) adalah bantuan dasar untuk membantu menyelamatkan nyawa bagi penderita cardiac arrest secara mendadak. Pelaksanaan RJP mampu mencegah defisit neurologis dan meningkatkan kualitas hidup individu setelah cardiac arrest (Morton, Fortaine, Hudak \& Gallo, 2011). Beberapa tahun terakhir telah terbukti bahwa pasien yang menderita cardiac arrest bergantung kualitas RJP baik kedalaman dan ritme kompresi yang dilakukan untuk menyelamatkan nyawa. Irama kompresi yang optimal adalah 100-120 bpm, rasanya cukup berat dan sulit dipertahankan tanpa adanya bimbingan pada orang yang melakukan kompresi dada (Mancini et al., 2015)

Pedoman American Heart Association (AHA) memberikan strategi berbasis bukti yang dapat digunakan dalam perawatan darurat kardiovaskular. Fokus pedoman AHA adalah memastikan kualitas RJP yang dilakukan (American Heart Association, 2020). Jika kompresi dada dilakukan secara benar, konsisten, dan membatasi jumlah penghentian kompresi maka RJP akan membantu memulihkan perfusi jaringan (Meaney et al., 2013). Namun, jika jumlah kompresi dada tidak mencukupi maka akan menurunkan tingkat kelangsungan hidup seseorang (Woollard et al., 2012). Kompresi dada yang berlebihan dapat menyebabkan tulang dada meregang dan berdampak negatif pada jumlah darah yang kembali ke jantung (Zhou et al., 2014). AHA (2020) menyarankan pemberian kompresi dada harus dengan kecepatan antara 100-120 bpm sehingga pemberian secara tepat akan mampu mempertahankan aliran darah setelah serangan jantung (Hafner et al., 2012).

Ada beberapa cara untuk menjaga kualitas kompresi RJP agar tetap stabil dan akurat, antara lain melalui aktivitas latihan RJP seperti biasa tanpa musik dan latihan seperti biasa dengan musik yaitu dengan mendengarkan musik yang memiliki kecepatan ritmis 100 bpm (Darmawan et al., 2018; Kim et al., 2017). Kedua metode menjadi pilihan untuk dapat digunakan karena bersifat sederhana, hemat biaya, dan mudah diterapkan saat kondisi apapun. Berdasarkan penelitian baru-baru ini yang dilakukan pada profesional medis dengan menggunakan skenario cardiac arrest. Penggunaan musik menjadi pilihan yang dapat memandu penolong dalam mengatur irama kompresi sesuai dengan rekomendasi AHA (Mancini et al., 2015).

Studi menunjukkan hasil yang beragam satu studi menyimpulkan bahwa musik dapat mengarahkan pada kecepatan kompresi RJP, sementara penelitian lain terhadap dokter dan perawat hasil menunjukkan kecepatan kompresi melebihi dari yang di rekomendasikan bahkan setelah menerima instruksi musik "Stayin Alive" (Zhao et al., 2019; Pellegrino et al., 2021). Musik "Stayin Alive" menjadi salah satu musik yang direkomendasikan oleh AHA memiliki irama 103 bpm. Adanya penggunaan musik dalam pelaksanaan RJP diyakini mampu memberikan memori terutama terkait irama saat dilakukannya kompresi RJP (Kim et al., 2017; Hafner et al., 2015). Namun, belum ada penelitian yang jelas tentang keuntungan atau efek musik "Stayin Alive" dibandingkan dengan metode pendidikan RJP lainnya bagi mahasiswa keperawatan.

Pendidikan keperawatan bertujuan untuk melatih mahasiswa menjadi perawat profesional dengan kompetensi inti yang dibutuhkan yaitu keperawatan lapangan dan untuk tujuan ini pendidikan menyediakan ruangan 
kelas dan lapangan klinis. Pendidikan yang diberikan kepada mahasiswa bertujuan untuk meningkatkan pengetahuan, keterampilan, dan sikap melalui pembelajaran kelas dan praktikum klinis (Eun \& Hye Young, 2017). Pelaksanaan RJP sesuai dengan kompetensi AIPNI (2010) yang menyatakan bahwa mahasiswa Sarjana keperawatan harus mampu melakukan tindakan RJP. Alasannya dikarenakan kemampuan melakukan RJP merupakan kemampuan dasar yang harus dimiliki perawat.

Berdasarkan studi pendahuluan, peneliti menemukan bahwa evaluasi kemampuan mahasiswa keperawatan STIKes Muhammadiyah Palembang masih 75\% di bawah standar penilaian kelulusan dalam pelaksanaan RJP terutama dinilai dari ketepatan, kedalaman, dan frekuensi kecepatan kompresi yang dinilai melalui lembar SOP. Oleh karena itu, peneliti tertarik untuk mempelajari pengaruh musik "Stayin Alive" terhadap kualitas kompresi RJP bagi mahasiswa keperawatan.

\section{METODOLOGI}

Penelitian ini merupakan jenis penelitian kuantitatif dengan Metode QuasyExperiment Pretest Posttest with Control Group Design. Teknik pengambilan sampel secara total sampling pada seluruh mahasiswa Profesi Ners STIKes Muhammadiyah Palembang yang berjumlah 70 orang. Selanjutnyasampelpenelitian dibagi menjadi dua kelompok yaitu kelompok intervensi dan kelompok kontrol dengan cara melakukan randomisasi secara stratified random sampling. Kelompok intervensi berjumlah 36 orang, sedangkan kelompok kontrol 34 orang. Hal ini dikarenakan 2 orang pada kelompok kontrol memenuhi kriteria drop out karena tidak dapat mengikuti kegiatan posttest

Implementasi penelitian kelompok intervensi adalah menjelaskan kompresi RJP saat mendengarkan musik "Stayin Alive" yang memiliki kecepatan ritme 103 bpm sebagai pengatur ritme kompresi, sedangkan pada kelompok kontrol, kompresi RJP dilakukan tanpa musik tetapi menggunakan metode penghitungan yang umum digunakan yaitu 'Rule of Five". Dalam praktik perhitungannya yaitu (satu, dua, tiga, empat, satu, satu, dua, tiga, empat, dua, satu, dua, tiga, empat, tiga, satu, dua, tiga, empat, empat, satu, dua, tiga, empat, lima, satu, dua, tiga, empat, enam). Pemberian praktik RJP dilakukan pada setiap subjek penelitian sesuai kelompok sampel. Subjek penelitian akan mempraktikan sampai mereka mampu mengikuti irama yang ditetapkan pada kelompok intervensi atau kelompok kontrol.

Penilaian kualitas kompresi RJP dilakukan dengan menghitung ketercapaian frekuensi kecepatan dan kedalaman saat RJP dilakukan oleh setiap subjek penelitian. Penilaian hasil penelitian dilakukan dua kali pretest segera setelah pemberian teori dan praktik RJP dan posttest 1 hari setelah pretest dilakukan. Lamanya waktu penelitian yaitu mulai tanggal 14 Sampai 16 Juli 2019.

Instrumen yang digunakan adalah maneken RJP yang dilengkapi indikator lampu. Penilaian frekuensi dihitung dengan menggunakan counter, sedangkan untuk ketercapaian kedalaman kompresi RJP menggunakan indikator lampu maneken. Hasil pengamatan yang telah dilakukan oleh peneliti kemudian dicatat di lembar observasi perhitungan frekuensi dan ketercapaian kedalaman kompresi RJP.

Data hasil yang sudah didapatkan diolah dengan statistik IBM SPSS 22. Paired t-test digunakan untuk menguji perbedaan antara hasil pretest dan posttest RJP frekuensi kompresi dari kelompok intervensi. Hal ini dikarena data berdistribusi normal, sedangkan Uji Wilcoxon digunakan untuk menguji perbedaan hasil pretest dan posttest frekuensi kompresi kelompok 
kontrol, serta ketercapaian kedalaman kompresi RJP baik kelompok intervensi maupun kelompok kontrol. Selanjutnya Uji Mann Whithney digunakan untuk menguji perbedaan frekuensi dan ketercapaian kedalaman kompresi RJP baik pada kelompok intervensi maupun kelompok kontrol karena data pada kedua kelompok tidak berdistribusi dengan normal.

\section{HASIL}

Berdasarkan analisis penelitian didapatkan hasil sebagai berikut:

Tabel 1. Karakteristik Subyek Penelitian

\begin{tabular}{|c|c|c|c|c|c|}
\hline \multirow{2}{*}{\multicolumn{2}{|c|}{ Variabel }} & \multicolumn{2}{|c|}{ Kelompok Intervensi } & \multicolumn{2}{|c|}{ Kelompok Kontrol } \\
\hline & & $n$ & $\%$ & $n$ & $\%$ \\
\hline \multicolumn{6}{|c|}{ Jenis Kelamin } \\
\hline- & Laki-laki & 14 & $38,90 \%$ & 14 & $41,20 \%$ \\
\hline- & Perempuan & 22 & $61,10 \%$ & 14 & $58,80 \%$ \\
\hline \multirow{2}{*}{\multicolumn{2}{|c|}{ Variabel }} & \multicolumn{2}{|c|}{ Kelompok Intervensi } & \multicolumn{2}{|c|}{ Kelompok Intervensi } \\
\hline & & $\mathbf{n}$ & Mean (kg) & $\mathbf{n}$ & Mean (kg) \\
\hline \multicolumn{6}{|c|}{ Berat Badan } \\
\hline- & Laki-laki & 14 & $65,86 \%$ & 14 & $63,00 \%$ \\
\hline- & Perempuan & 22 & $45,50 \%$ & 20 & $55,10 \%$ \\
\hline
\end{tabular}

Berdasarkan hasil analisis tabel 1 baik kelompok intervensi maupun kelompok kontrol dominan berjenis kelamin perempuan dengan perbandingan perempuan pada kelompok intervensi yaitu 22 orang $(61,1 \%)$, sedangkan pada kelompok kontrol sebanyak 20 orang
(58,8\%). Dominan berat badan baik kelompok intervensi maupun kelompok kontrol dominan berjenis kelamin laki-laki lebih berat dengan nilai mean $65,86 \mathrm{~kg}$ untuk kelompok intervensi dan nilai mean $63 \mathrm{~kg}$ untuk kelompok kontrol.

Tabel 2. Perbedaan Frekuensi dan Kedalaman RJP Sebelum dan Sesudah pada Kelompok Intervensi dan Kelompok Kontrol

\begin{tabular}{|c|c|c|c|c|c|}
\hline & Variabel & $\mathbf{n}$ & SD & Mean & p-value \\
\hline \multicolumn{6}{|c|}{ Kelompok Intervensi } \\
\hline - & Frekuensi RJP pre intervensi & 36 & 15,739 & 141,056 & \multirow[t]{2}{*}{0,000} \\
\hline- & Frekuensi RJP post intervensi & 36 & 17,204 & 105,75 & \\
\hline & Variabel & $\mathbf{n}$ & Median & Min - Max & Nilai $\mathbf{P}$ \\
\hline \multicolumn{6}{|c|}{ Kelompok Kontrol } \\
\hline - & Frekuensi RJP pre intervensi & 34 & 141,0 & $103-300$ & \multirow{2}{*}{0,001} \\
\hline - & Frekuensi RJP post intervensi & 34 & 123,0 & $95-150$ & \\
\hline
\end{tabular}




\begin{tabular}{lcccc}
\hline \multicolumn{1}{c}{ Variabel } & $\mathbf{n}$ & Median & Min - Max & p-value \\
\hline Kelompok Intervensi & & & & \\
$-\quad \quad$ Kedalaman RJP pre intervensi & 36 & 86,0 & $0-181$ & 0,013 \\
- $\quad 36$ & 57,5 & $0-126$ & \\
Kedalaman RJP post intervensi & & & & \\
- $\quad$ Kedalaman RJP pre intervensi & 34 & 72,0 & $0-151$ & 0,001 \\
\hline$\quad \quad$ Kedalaman RJP post intervensi & 34 & 54,5 & $0-149$ & \\
\hline
\end{tabular}

Berdasarkan hasil analisis tabel 2 didapatkan bahwa pada kelompok intervensi didapatkan $p$-value $=0,000(\mathrm{p}<0,005)$ dan pada kelompok kontrol $p$-value $=0,001(\mathrm{p}<0,005)$ yang berarti bahwa adanya pengaruh yang signifikan baik kelompok intervensi maupun kelompok kontrol terhadap frekuensi RJP. Adapun untuk analisis terhadap kedalaman RJP didapatkan hasil pada kelompok intervensi $p$-value $=0,013$ $(\mathrm{p}<0,005)$ dan kelompok kontrol $p$-value $=0,001$ $(p<0,005)$ yang berarti bahwa baik kelompok intervensi maupun kelompok kontrol adanya pengaruh yang signifikan terhadap kedalaman RJP.

Tabel 3. Perbedaan Frekuensi dan Kedalaman RJP antara Kelompok Intervensi Musik dengan Kelompok Kontrol

\begin{tabular}{lcccc}
\hline \multicolumn{1}{c}{ Variabel } & n & Median & Min - Max & p-value \\
\hline Frekuensi RJP & & & & \\
$-\quad$ Kelompok Intervensi & 36 & 141,0 & $103-300$ & \\
$-\quad$ Kelompok Kontrol & 34 & 123,0 & $95-150$ & 0,381 \\
Kedalaman RJP & & & & \\
$-\quad$ Kelompok Intervensi & 36 & 43,5 & $0-125$ & 0,295 \\
$-\quad$ Kelompok Kontrol & 34 & 61,5 & $0-136$ & \\
\hline
\end{tabular}

Berdasarkan analisis tabel 3 dari hasil uji statistik diketahui bahwa perbedaan rerata frekuensi dan kedalaman subyek penelitian antara kelompok intervensi musik dengan kelompok kontrol $p$-value $=0,381(\mathrm{p}>0,05)$ untuk frekuensi dan $p$-value $=0,295(\mathrm{p}>0,05)$ untuk kedalaman yang berarti tidak ada perbedaan yang signifikan frekuensi dan kedalaman RJP antara kedua kelompok.

\section{PEMBAHASAN}

1) Karakteristik Subyek Penelitian

a. Jenis Kelamin

Hasil penelitian yang dilakukan peneliti menunjukkan hasil subjek penelitian laki-laki cenderung lebih stabil dan mencapai nilai yang di tetapkan AHA 2015 dari segi frekuensi dan kedalaman kompresi yang dinilai dari pretest dan posttest pada kedua kelompok.

Penelitian ini sejalan dengan penelitian terdahulu terlihat adanya hubungan antara jenis kelamin dengan kualitas kompresi RJP ( $p$-value $=0,001 ; \alpha<0,05) . \quad$ Subjek penelitian laki-laki lebih mampu mempertahankan kualitas tinggi kompresi dibandingkan perempuan $(\mathrm{OR}=70 ; \quad \mathrm{CI}=8,528-574,548) . \quad$ Hasil uji multivariat menunjukkan faktor dominan berhubungan dengan kualitas 
kompresi RJP adalah jenis kelamin dengan $(\mathrm{OR}=0,01 ; \mathrm{CI}=8,644-1144,269)$. Jenis kelamin laki-laki 0,001 kali melakukan kompresi berkualitas rendah karena adanya faktor kesadaran diri dan kelelahan. Hasil lain menunjukkan hal yang sama adanya hubungan jenis kelamin dengan tingkat kompresi dada. Dalam penelitian ini, terlihat hubungan yang signifikan antara jenis kelamin dan tingkat kompresi dada $(p$-value $=0,000)$ (Ardiansyah et al., 2019).

Adanya perbedaan nilai kualitas kompresi antara laki-laki dan perempuan dikarenakan perbedaan kekuatan otot ekstremitas perempuan 40\%-60\% lebih lemah dibandingkan laki-laki dan 25\%$30 \%$ otot ekstremitas bawah perempuan lebih lemah dibandingkan ototekstremitas bawah laki-laki (Kenney, Wilmore \& Costill, 2015). Perbedaan lainnya yaitu adanya perbedaan komposisi tubuh antara laki-laki dan perempuan. Lakilaki memiliki massa kerangka dan lemak bebas lebih tinggi dibandingkan perempuan yang memiliki jumlah lemak tubuh yang lebih tinggi (Hall, 2015). Penelitian lainnya siswa perempuan bahkan tidak mencapai kedalaman yang disarankan $5 \mathrm{~cm}$ sedangkan siswa lakilaki menunjukkan kinerja yang cukup dalam mencapai kedalaman kompresi (Semeraro et al., 2017).

Hasil penelitian lainnya terhadap partisipan perempuan rata-rata nilai kecepatan kompresi sebagian besar terlalu cepat melebihi standar kualitas kecepatan kompresi artinya sebagian besar partisipan memiliki nilai rata-rata kompresi dibawah standar (Sutono et al., 2015). Peneliti berpendapat faktor gender kemungkinan dapat mempengaruhi kedalaman dan kecepatan kompresi dada. Keadaan ini dikarenakan kompresi dada yang dilakukan dengan terlalu cepat menyebabkan kelelahan dini dan kedalaman kompresi kurang dari $5 \mathrm{~cm}$ (Semeraro et al., 2017).

b. Berat Badan

Berdasarkan hasil penelitian mahasiswa dengan berat badan lebih berat mampu mencapai kedalan sesuai standar yaitu 4-5 cm dan tidak begitu mempengaruhi kecepatan RJP. Penelitian Ardiansyah et al (2019) menunjukkan hasil adanya hubungan antara kualitas kompresi RJP dengan IMT penolong $(p=0,018 ; \alpha<0,05)$. IMT kategori normal memiliki kualitas kompresi lebih tinggi dibandingkan IMT kategori lebih $(\mathrm{OR}=3,571 ; \quad \mathrm{CI}=1,346-9,475) . \quad$ Hasil lanjutan terlihat adanya hubungan antara kelelahan dengan kualitas kompresi RJP ( $p$-value $=0,001 ; \alpha<0,05)$. Penolong kategori kelelahan mampu melakukan kompresi RJP dengan kualitas lebih tinggi dibandingkan kelelahan berat $(\mathrm{OR}=6,818 ; \mathrm{CI}=2,421-19,201)$.

Hal ini disebabkan karena kompresi dada membutuhkan daya yang berfokus vertikal di atas sternum ke kedalaman 4-5 cm. Jumlah daya yang dibutuhkan untuk menekan tulang dada dengan sampai mencapai 4-55 cm adalah sekitar 500 N (Hasegawa et al., 2014). Kekuatan kompresi dada selama RJP biasanya dihasilkan dengan menggunakan gravitasi dan pinggul torsi fleksi. Bagian tubuh atas akan dapat meningkat tekanan jika penolong menggunakan berat tubuh bagian atas ke bawah dibantu dengan gravitasi dan mengggunakan torsi ekstensi pinggul untuk menahan 
dekompresi gaya gravitasi inersia. Kelompok dengan berat tubuh ringan menghasilkan gaya yang diperlukan untuk tekanan dengan memanfaatkan trapezius, rektus perut, eksternal otot samping, dan rektus femoris. dekompresi, kekuatan spinae erector dan ini mungkin akan menyebabkan peningkatan kelelahan fisik pada kelompok ringan dibandingkan dengan kelompok yang memiliki berat badan lebih berat. Alasan inilah yang menyebabkan penyelamat yang lebih ringan akan cepat mengalami kelelahan secara obyektif saat melakukan kompresi RJP, sehingga kualitas kompresi dada menjadi buruk (Hasegawa et al., 2020).

Penelitian lain yang dilakukan Hasegawa et al (2014) bahwa mayoritas peserta dalam penelitian ini memiliki berat kurang dari 70 kilogram memberikan kompresi efektif paling sedikit selama melakukan resusitasi. Oleh karena itu, semakin ringan subjek semakin kurangnya kedalaman kompresi yang mereka lakukan, dan semakin cepat mereka melakukan kompresi maka peserta akan merasakan lelah selama resusitasi. Hasil serupa dalam penelitian Krikscionaitiene et al (2013never trained in basic life support (BLS) bahwa jumlah tekanan yang diberikan oleh subjek dengan berat yang relatif lebih ringan sangat rendah.

Berdasarkan beberapa penjelasan sebelumnya dapat disimpulkan bahwa seiring penurunan berat badan, subjek mengalami kelelahan lebih cepat disertai penurunan kualitas resusitasi. Hal ini disebabkan karena mayoritas subjek yang termasuk dalam sampel penelitian adalah perawat wanita dengan berat badan yang agak rendah. Dalam studi lain, peserta dengan BMI yang lebih tinggi dan indeks kebugaran fisik yang baik merasa kurang lelah selama melakukan RJP (Russo et al., 2011).

\section{2) Pengaruh Intervensi Musik Stayin Alive terhadap Frekuensi dan Kedalaman RJP}

Berdasarkan hasil penelitian yang dilakukan peneliti diantara kedua metode baik musik "Stayin Alive" maupun kelompok kontrol yang menggunakan metode "Rule of Five" menunjukkan hasil tidak ada perbedaan dengan masing-masing nilai untuk frekuensi ( $p$-value $=0,381)$ dan kedalaman ( $p$-value $=0,295)$. Akan tetapi, jika dilihat dari nilai peningkatan distribusi frekuensi pre-posttest kelompok intervensi musik lebih mengalami peningkatan jumlah sesuai dengan standar AHA (100-120X/ mnt) yaitu $8,3 \%$ menjadi $41,7 \%$ daripada kelompok kontrol dari $14,7 \%$ menjadi $38,2 \%$. Hal ini dikarenakan dengan adanya musik memudahkan subjek penelitian dalam mengingat irama kecepatan dengan akurat 100 denyut / menit (Kim et al., 2017).

Semakin sering seseorang terpapar mendengarkan musik terutama yang sudah populer akan membantu seseorang untuk bisa mengulang mengingat kembali suara yang didengarkan (Hafner et al., 2015). Tujuan AHA menggunakan musik 103 bpm yang berjudul "Stayin alive" adalah untuk menghasilkan tingkat kompresi 100 kali untuk orang awam. Penjelasan lainnya adalah karena ketika menggunakan musik dalam pembelajaran RJP, tingkat kompresi lebih terkonsentrasi pada target bpm. Oleh karena itu, berdasarkan penjelasan tersebut musik 100-110 bpm cocok untuk pendidikan RJP dengan menggunakan musik (Kim et al., 2017).

Penelitian lain menggambarkan 
hasil ketika tes yang sama dilakukan di Grup B tanpa panduan audio Mean Compression Depth (MCD) secara signifikan meningkat, sedangkan di Grup A dengan menggunakan nada audio menyebabkan Mean Compression Rate (MCR) dan MCD menurun. Hal ini dikarenakan MCR dari tes dasar $\geq 110$ bpm tampaknya berkurang ketika RJP dengan panduan nada audio dilakukan pada kecepatan 100 bpm (Hong \& Oh, 2019). Jika percobaan yang sama dilakukan beberapa bulan setelah pemberian pendidikan RJP mungkin saja hasil yang berbeda yang akan didapatkan. Tidak ada bukti seberapa besar kualitas RJP ketika MCR adalah $\geq 100$ bpm. Namun, tampaknya MCR meningkat sesuai dengan pengaturan kecepatan nada audio yang ditetapkan (Hong \& Oh, 2019). Adanya peningkatan MCR melebihi pedoman AHA dapat menyebabkan peningkatan rata-rata karbondioksida. Sebaliknya, semakin meningkatnya tingkat kompresi dada menyebabkan menurunnya konsentrasi karbondioksida terutama saat adanya panduan audio dalam pelaksanaan RJP (Hamrick et al., 2014).

Adanya alat bantu musik sebagai memori dalam melakukan kompresi dada sesuai pedoman pelaksanaan RJP. Selama penilaian awal, subjek secara efektif mempertahankan tingkat kompresi yang memadai sambil langsung mendengarkan alat musik. Selanjutnya, subyek merasa bahwa menggunakan alat musik meningkatkan kemampuan mereka untuk melakukan RJP pada pasien sesuai dengan pedoman AHA (Kim et al., 2017).

\section{SIMPULAN DAN SARAN}

Baik kelompok intervensi dengan musik "Stayin Alive" maupun kelompok kontrol dengan Rule of Five mempunyai kemampuan yang sama terhadap peningkatan kualitas frekuensi dan kedalaman. RJP. Oleh karena itu, kedua metode pembelajaran dan pelatihan kompresi RJP dapat dijadikan rekomendasi dalam pelaksanaan praktikum RJP pada mahasiswa perawat

\section{DAFTAR PUSTAKA}

American Heart Association. (2020). Highlights of the 2020 American Heart Association Guidlines For CPR and EGC. American Heart Association.

Ardiansyah, F., Nurachmah, E., \& Adam, M. (2019). PENDAHULUAN Henti jantung kesehatan tergantung dari bantuan hidup dasar dan sebagai masalah tahun bantuan hidup lanjut ( Paal et al ., 2012; Lee \& Low , 2010 ). Karakteristik high quality RJP dipengaruhi oleh kecepatan kompresi ( $5-6 \mathrm{~cm}$ ). Selain itu ,. Jurnal 'Aisyiyah Medika, 3(2), 123-137.

Darmawan, R. E., Sujianto, U., \& ROchana, N. (2018). Effects of neo automatic code on the accuracy of chest compression depths in cardiac arrest patients. Hiroshima Journal of Medical Sciences, 67(024), 161-165.

Eun, K., \& Hye Young, K. (2017). Effects of Simulation-based Education Combined Team-based Learning on Self-directed Learning, Communication Skills, Nursing Performance Confidence and Team Efficacy in Nursing Students. Journal of Korean Academy of Fundamentals of Nursing, 24(1), 39-50. https://doi. org/10.7739/jkafn.2017.24.1.39

Hafner, J. W., Jou, A. C., Wang, H., Bleess, B. B., \& Tham, S. K. (2015). Death before disco: The effectiveness of a musical metronome in layperson cardiopulmonary resuscitation training. Journal of Emergency Medicine, 48(1), 43-52. https://doi.org/10.1016/j. 
jemermed.2014.07.048

Hafner, J. W., Sturgell, J. L., Matlock, D. L., Bockewitz, E. G., \& Barker, L. T. (2012). Stayin' alive: A novel mental metronome to maintain compression rates in simulated cardiac arrests. Journal of Emergency Medicine, 43(5), e373-e377. https://doi. org/10.1016/j.jemermed.2012.01.026

Hall, J. E. (2015). Guyton and Hall Textbook of Medical Physiology (13th ed.). Elsevier Health Sciences.

Hamrick, J. L., Hamrick, J. T., Lee, J. K., Lee, B. H., Koehler, R. C., \& Shaffner, D. H. (2014). Efficacy of chest compressions directed by end-tidal $\mathrm{CO} 2$ feedback in a pediatric resuscitation model of basic life support. Journal of the American Heart Association, 3(2), 1-12. https://doi. org/10.1161/JAHA.113.000450

Hasegawa, T., Daikoku, R., Saito, S., \& Saito, Y. (2014). Relationship between weight of rescuer and quality of chest compression during cardiopulmonary resuscitation. Journal of Physiological Anthropology, 33(1), 1-7. https://doi.org/10.1186/18806805-33-16

Hasegawa, T., Okane, R., Ichikawa, Y., Inukai, S., \& Saito, S. (2020). Effect of chest compression with kneeling on the bed in clinical situations. Japan Journal of Nursing Science, 17(2), 1-9. https://doi. org/10.1111/jjns. 12314

Hong, J. Y., \& Oh, J. H. (2019). Variations in chest compression time, ventilation time and rescuers' heart rate during conventional cardiopulmonary resuscitation in trained male rescuers. Clinical and Experimental Emergency Medicine, 6(1), 31-35. https://doi.org/10.15441/ceem.17.280

Kenney, W. L., Wilmore, J. H., \& Costill, D. L. (2015). Physiology sport and exercise (Sixth). Human Kinetics.
Kim, K. W., Kim, J. H., Choe, W. J., Kim, J. Y., Lee, S. Il, Kim, K. T., Park, J. S., Kim, J. W., Lee, Y., Lee, J. H., \& Park, J. (2017). Effectiveness of 100 beats per minute music on cardiopulmonary resuscitation compression rate education: A manikin study. Hong Kong Journal of Emergency Medicine, 24(1), 12-17. https://doi. org/10.1177/102490791702400102

Krikscionaitiene, A., Stasaitis, K., Dambrauskiene, M., Dambrauskas, Z., Vaitkaitiene, E., Dobozinskas, P., \& Vaitkaitis, D. (2013). Can lightweight rescuers adequately perform CPR according to 2010 resuscitation guideline requirements? Emergency Medicine Journal, 30(2), 159-160. https://doi. org/10.1136/emermed-2011-200634

Mancini, M. E., Diekema, D. S., Hoadley, T. A., Kadlec, K. D., Leveille, M. H., McGowan, J. E., Munkwitz, M. M., Panchal, A. R., Sayre, M. R., \& Sinz, E. H. (2015). 2015 AHA Guidelines update for CPR. In American Heart Associationtion (Vol. 132, Issue 18). https://www.cercp. org/images/stories/recursos/Guias 2015/ Guidelines-RCP-AHA-2015-Full.pdf

Meaney, P. A., Bobrow, B. J., Mancini, M. E., Christenson, J., De Caen, A. R., Bhanji, F., Abella, B. S., Kleinman, M. E., Edelson, D. P., Berg, R. A., Aufderheide, T. P., Menon, V., \& Leary, M. (2013). Cardiopulmonary resuscitation quality: Improving cardiac resuscitation outcomes both inside and outside the hospital: A consensus statement from the American heart association. Circulation, 128(4), 417-435. https://doi.org/10.1161/ CIR.0b013e31829d8654

Morton, P.G., Fortaine, D. K., Hudak, C. M., \& Gallo, B. M. (2011). Keperawatan Kritis: Pendekatan Asuhan Holistik (Nike. E.W 
(ed.); 8 vol 1). EGC.

Pellegrino, J. L., Vance, J., \& Asselin, N. (2021).

The Value of Songs for Teaching and Learning Cardiopulmonary Resuscitation (CPR) Competencies: A Systematic Review. Cureus, 13(5). https://doi. org/10.7759/cureus. 15053

Russo, S. G., Neumann, P., Reinhardt, S., Timmermann, A., Niklas, A., Quintel, M., \& Eich, C. B. (2011). Impact of physical fitness and biometric data on the quality of external chest compression: A randomised, crossover trial. $B M C$ Emergency Medicine, 11(1), 20. https:// doi.org/10.1186/1471-227X-11-20

Semeraro, F., Frisoli, A., Loconsole, C., Mastronicola, N., Stroppa, F., Ristagno, G., Scapigliati, A., Marchetti, L., \& Cerchiari, E. (2017). Kids (learn how to) save lives in the school with the serious game Relive. Resuscitation, 116, 27-32. https://doi.org/10.1016/j. resuscitation.2017.04.038

Sutono, Ratnawati, R., \& Suharsono, T. (2015). Perbedaan nilai kompresi dada dan ventilasipada pelatihan resusiatasijantung paru mahasiswa S1 keperawatan dengan umpan balik instruktur, audiovisual dan kombinasi di Yogyakarta. Jurnal Ilmu Keperawatan, 3(2), 15.

Woollard, M., Poposki, J., McWhinnie, B., Rawlins, L., Munro, G., \& O’Meara, P. (2012). Achy breaky makey wakey heart? A randomised crossover trial of musical prompts. Emergency Medicine Journal, 29(4), 290-294. https://doi.org/10.1136/ emermed-2011-200187

Zhao, X., Nadkarni, L., Ford, B., \& Kessler, D. (2019). Utility of a musical mnemonic to teach CPR compression rate based on musical skills. BMJ Simulation and Technology Enhanced Learning, 5(3), 180-181. https://doi.org/10.1136/ bmjstel-2017-000275

Zhou, X. L., Duan, X. W., Zhao, Y., Jiang, C., Xu, P., Jiang, S., \& Ni, S. Z. (2014). Medical students do not adversely affect the quality of cardiopulmonary resuscitation for ED patients. American Journal of Emergency Medicine, 32(4), 306-310. https://doi. org/10.1016/j.ajem.2013.12.007 